\title{
O tema da homossexualidade em João Antônio e Caio Fernando Abreu
}

\author{
Flávia Merighi Valenciano ${ }^{1}$
}

RESUMO: Este ensaio reflete sobre o tema da homossexualidade no conto "Galeria Alaska", de João Antônio, e "Caçada", de Caio Fernando Abreu. Tais contos revelam características bastante relevantes tanto da obra ficcional de cada um destes autores brasileiros quanto de sua relação com o jornalismo e, em certa medida, de suas experiências pessoais.

ABSTRACT: This essay reflects about the theme of homosexuality on short story "Galeria Alaska", by João Antônio, and "Caçada", by Caio Fernando Abreu. Such stories reveal very relevant characteristics in each of these Brazilian authors, both in their fictional work and in their relationship to journalism, besides reveal to some extent their personal experiences.

PALAVRAS-CHAVE: João Antônio; Caio Fernando Abreu; Literatura Brasileira; Jornalismo; Homossexualidade.

KEYWORDS: João Antônio; Caio Fernando Abreu; Brazilian Literature; Jornalism; Homosexuality.

Literatura de dentro para fora. Isso é pouco. Realismo crítico. É pouco. Romance-reportagem-depoimento.

Ainda pouco. Pode ser tudo isso trançado, misturado, dosado, conluiado, argamassado uma coisa da

outra. E será bom. Perto da mosca. A mosca - é quase certo - está no corpo-acorpo com a vida.

Escrever é sangrar. Sempre, desde a Bíblia. Se não sangra, é escrever?

(João Antônio, “Corpo-a-corpo com a vida”, 03 de novembro de 1976).

\footnotetext{
1 Mestranda em Estudos Comparados de Literaturas de Língua Portuguesa. FFLCH.USP. E-mail: flaviamerighi@usp.br
} 
Não tem demônio nenhum se interpondo entre você e a máquina. O que tem é uma questão de honestidade básica. Essa perguntinha: você quer mesmo escrever? Isolando as cobranças, você continua querendo? Então vai, remexe fundo (...) Tira sangue com as unhas. $E$ não importa a forma, não importa a "função social" (...), não importa que, a princípio, seja apenas uma espécie de auto-exorcismo. Mas tem que sangrar abun-dan-te-men-te.

(Caio Fernando Abreu, Carta a Zézim, 22 de dezembro de 1979).

Entre as décadas de 1960 e 1980, houve uma explosão considerável da ficção realizada por jornalistas no Brasil, em que se destacam alguns nomes como Antonio Callado, Caio Fernando Abreu, Carlinhos Oliveira, Ferreira Gullar, João Antônio e Otto Lara Resende, para citar alguns dos principais. Em meio à ditadura militar vigente no país e aos crescentes problemas sociais, grande parte dos escritores que se dedicava ao jornalismo entrou em conflito com algumas questões que, em maior ou menor grau, incidiram em toda a sua produção ficcional.

A reflexão de João Antônio sobre a função do jornalismo e, conseqüentemente, da ficção a partir do "levantamento de realidades brasileiras” (ANTÔNIO, 1976:143) encontra-se no "texto-manisfesto" que encerra Malhação do Judas carioca (1976), "Corpo-a-corpo com a literatura". Nesse texto, o autor invoca uma "escrita guerreira" por parte dos jornalistas e ficcionistas de sua época, "Uma literatura que se rale nos fatos e não que rele neles" (ANTÔNIO, 1976:146). Em meio à necessidade de discutir essas realidades brasileiras e seus protagonistas, a proposta do escritor é certeira:

Não será absolutamente necessário, para compreender - uma palavra superada; leia-se, por favor, enfrentar - o marginalismo individual dos que se debatem no futebol ou na polícia, alguém 
que assuma o mesmo gangsterismo, um semelhante (mas com visão crítica) individualismo? Um gangsterismo, um individualismo, um individualismo ao menos experimental. Que, ao escrever, dê a mesma porrada, como repórter, escritor, etc., que o bandido, o jogador, o traficante, o bicheiro e, especialmente e isso tudo - herói - dão para sobreviver. Assim, uma literatura de murro e porrada. Um corpo-a-corpo com a vida. (ANTÔNIO, 1976:148; destaque meu).

O projeto literário do autor, tanto no âmbito ficcional quanto no jornalístico, emerge da necessidade de se assumir o olhar desse "herói”" que luta pela sobrevivência cotidianamente, ou seja, de se exercitar esse "individualismo experimental" do corpo-a-corpo com a vida.

O escritor Caio Fernando Abreu, por sua vez, mantinha uma relação bastante complicada com a imprensa: não suportava as pressões do jornalismo diário e possuía o “(...) sentimento de inadequação do artista dentro das redações (...)” (COSTA, 2005:333). Originário da classe média e nascido no interior do Rio Grande do Sul, ${ }^{2}$ Abreu enfrentou a maior cidade do Brasil para trabalhar como jornalista na então recente revista Veja. Porém, encontrou inúmeras dificuldades, especialmente financeiras, não só em seus primeiros anos em São Paulo, mas também na capital carioca. Em uma de suas inúmeras cartas, ${ }^{3}$ Caio Fernando Abreu afirma que o escritor e a escritora brasileiros são convidados, todos os dias que acordam, a desistir de sua vocação.

Ainda, Abreu tinha um certo repúdio à chamada "vida literária" e às relações que ali se estabeleciam, o que fica evidente em uma das cartas dirigidas a seu amigo e escritor Luiz Fernando Emediato, em 22 de agosto de 1977:

E essa paranóia, essa desconfiança, esse medo do outro tem sido meu leitmotif nos últimos tempos. Vem de fora pra dentro porque a cidade grande, o trabalho no jornal, o ninho de cobras da, aarrgh!, vida literária só fazem aumentar isso (...) (ABREU, 2002:492).

\footnotetext{
2 Caio Fernando Abreu nasceu em Santiago do Boqueirão.

3 ABREU, Caio Fernando. Cartas. Organização: Italo Moriconi. Rio de Janeiro: Aeroplano, 2002.
} 
É possível encontrar em inúmeras cartas escritas pelo autor referências relacionadas a essa "vida literária" de que tanto desgostava e com que se incomodava profundamente. Tal comportamento está intimamente vinculado à postura do escritor no que concerne à sua literatura: Caio Fernando Abreu não se guiava por modelos préestabelecidos e beletrismos, que também eram veementemente criticados por João Antônio.

O "individualismo experimental" joãoantoniano está presente, sem dúvida alguma, no projeto literário de Caio Fernando Abreu. No entanto, é necessário refletir de que maneira a postura dos referidos escritores resulta em uma "literatura do corpo-a-corpo" e em quais são seus pontos de convergência e divergência.

O escritor João Antônio convivia diariamente com jogadores de sinuca, merdunchos, ${ }^{4}$ pingentes ${ }^{5}$ e malandros; Caio Fernando Abreu foi hippie e viveu entre "(...) as instigações pop-contraculturais e "malditas" ou "marginais" dos anos 70 e a pasteurização juvenil e mística dos 90" (MORICONI, In: ABREU, 2002:11). Ambos assimilaram essas realidades e transcenderam-nas em seus textos, recriando a linguagem própria dos tipos sociais e dos espaços ali representados. No entanto, as realidades pintadas por ambos são distintas e correspondem a diferentes questões de caráter urgente. Neste trabalho, procuraremos compreender de que modo os escritores retratam a questão da homossexualidade e do preconceito sexual, tendo como foco os contos "Galeria Alaska", 6 de João Antônio, e "Caçada", 7 de Abreu.

Para João Antônio, escrever é sangrar; para Caio Fernando Abreu, é tirar sangue com as unhas. Percorramos, pois, as veias do corpo-acorpo desses dois escritores-chave da literatura e do jornalismo nacionais das últimas décadas do século XX.

\footnotetext{
4 ANTÔNIO, João. Casa de Loucos. Rio de Janeiro: Civilização Brasileira, 1976, p. 55.

5 ANTÔNIO, João. Malhação do Judas Carioca. Rio de Janeiro: Civilização Brasileira, 1976, pp. 24.

6 In: Malhação do Judas Carioca. Rio de Janeiro: Civilização Brasileira, 1975.

7 In: Pedras de Calcutá. São Paulo: Alfa-Omega, 1977.
} 


\section{O tema da homossexualidade: dois lados da mesma moeda}

Olho, olho aí, o país. O da gente, assim aturdido, mais parece uma criança em que todos, os de dentro e os de fora, batem.

(João Antônio, “Abraçado ao meu rancor").

Peço à aeromoça algumas revistas ou jornais brasileiros. Ela me traz uma

Manchete. Misses, futebol, parece horrivel. Então sinto medo. Por trás do cartão-postal imaginado, sol e palmeiras, há umjeito brasileiro que me aterroriza, o deboche, a grossura, o preconceito.

(Caio Fernando Abreu, “Lixo e Purpurina”).

O narrador do conto "Galeria Alaska”, de João Antônio, descreve com detalhes a noite do bairro de Copacabana e dos arredores dessa galeria, ponto de encontro dos homossexuais do Rio de Janeiro na década de 1970. Copacabana está adormecida, mas os olhos atentos do narrador percorrem todo o espaço:

Copacabana dorme de todo. Mesmo nestes cantos do Posto Seis, os de menor movimento, rumor, amores espúrios, trampolinagens, esporros, idas e vindas na noite, Copacabana dorme. Ou antes, na palavra dos freqüentadores da Galeria Alaska:

- A gente não dorme; desmaia (ANTÔNIO, 1976:10).

Esse narrador observador explora toda a área do bairro, bem como seus protagonistas, de um nascer do Sol a outro. Logo no início do texto, o autor revela-nos a situação da maioria dos trabalhadores daquele espaço: 
Um homem, quarenta anos, Otacílio, dez de galeria, vem de longe, do outro lado da cidade, do subúrbio bravo, Todos os Santos, muito calor, sol e mar nenhum. Carrega marmita feito livro debaixo do braço, apanha trem da Central do Brasil e um ônibus para Copacabana. Gasta, só aí, quase dois cruzeiros - e para ele é dinheiro (ANTÔNIO, 1976:11).

Por meio de recursos como o depoimento, o narrador relata-nos o mundo dos trabalhadores da Galeria; as dificuldades pelas quais passam e a luta diária pela sobrevivência são destacadas em todo o texto. Porém, o que nos chama a atenção é a forma com que o autor se refere às pessoas que freqüentam a noite nos arredores da Galeria Alaska:

O litro de leite sumiu do Rio, em seu lugar vieram os saquinhos plásticos, muito brancos, mais brancos a esta hora cinza, chumbo carregado, hora parada, neutra, a que os boêmios, os pederasta

$s$, os artistas da noite, as mulheres e seus cáftens, as curriolas da galeria chamam de rabo da manhã (ANTÔNIO, 1976:11; destaque meu).

O léxico utilizado pelo autor e a caricaturização de alguns tipos evidenciam uma perspectiva "de fora": João Antônio estampa em primeiro plano uma imagem caricaturizada dos homossexuais e lésbicas, vinculando a causa do "problema"8 exclusivamente à situação social em que esses homens e mulheres se encontram:

A moçada sai da Zona Norte ou dos subúrbios lá longe, toma suas luzes como modelo de vanguarda no Rio - no bairro se sabe vestir bem, beber o melhor (...). A meninada principia justamente na Galeria Alaska, certa de que com o físico, juventude, gingas e bossa, conseguirá o melhor em mulheres, boates, facilitações e exuberância (...). De comum, no entanto, a façanha é outra e, por falta de dinheiro, os rapazes do subúrbio começam deitando-se com pederastas (...) Atraídos pelas mulheres bonitas, elegantes ou coloridas pelo sol (...), acabam deitando-se com homossexuais, por dinheiro (...) (ANTÔNIO, 1976:17; destaque meu).

Fica evidente, pois, que o autor entende a homossexualidade presente naquele espaço como "falta de opção", e não como o simples

\footnotetext{
8 O conto "Galeria Alaska" encontra-se na parte do livro intitulada "Problema".
} 
desejo pelo mesmo sexo. Os meninos do subúrbio carioca teriam como única saída deitarem-se com os homossexuais moradores de Copacabana, com o objetivo de permanecerem no bairro. Segundo João Antônio, a situação dos meninos não muda, e eles permanecem com os "pederastas" durante muito tempo, ou até mesmo definitivamente. Nas palavras do autor, "Manter-se em Copacabana a qualquer custo, é necessário aproveitar-se de velhos pederastas endinheirados, mal amados e que ninguém quer” (ANTÔNIO, 1976:17). Como vemos, a temática da solidão dos homossexuais, bastante abordada por Caio Fernando Abreu em sua obra, é tratada pejorativamente por João Antônio.

O "corpo-a-corpo com a vida" revela-se a todo o momento em seu texto. O narrador relata os fatos como se estivesse acompanhando-os de perto:

Três e meia da manhã. O movimento e o rumor dos corpos magros e elegantes está no ponto, lá no interior da boate Sótão, apenas homossexuais masculinos. Dança-se, rostos colados e se namora, tranqüilamente, aos beijinhos (ANTÔNIO, 1976:22).

No entanto, o tom pejorativo é presença constante, assim como a questão da luta pela sobrevivência do povo oprimido e esquecido do subúrbio. A falta de opção levaria, portanto, os jovens da Zona Norte e dos demais subúrbios do Rio de Janeiro a buscarem a companhia dos “pederastas endinheirados”. Os últimos parágrafos do texto revelam-nos a relação de submissão de um casal homossexual, que representa tantos outros:

Dois, marido e mulher, sentados numa das mesas do Rio Jerez, defronte a um prato de comida. Como um cáften e sua marafona. $\mathrm{O}$ que leva jeito de macho, devora a comida gulosa, gostosamente. Bebe sorvendo, come sentindo. O outro, cara de cansaço e fome não tem direito sequer de tocar no prato. Segue cada bocado com olhos famintos, suplicantes. Mas deve obediência e engole seco. O macho é quem manda, embora o cansado e faminto é quem vai pagar. É a lei.

- Não enche (ANTÔNIO, 1976:22; destaque meu). 
Tanto o "cáften" quanto a sua "marafona" são peças da mesma engrenagem: ambos lutam para sobreviver em um país marcado pela desigualdade social. Porém, dentro da "lei" forjada pelas margens, sobressai-se o mais esperto e o mais forte, que submete o mais fraco às suas necessidades.

A falta de opção para obter um lugar melhor ao Sol e perto do mar levaria, pois, alguns jovens a submeterem-se ao relacionamento homossexual. Por sua vez, o narrador de "Caçada", conto de Caio Fernando Abreu, é onisciente e identifica-se consideravelmente com as personagens. O protagonista do conto encontra-se em um ambiente indefinido da noite carioca e percebe a presença de uma possível "caça":

Viu primeiro a medalha, corrente dourada confundida entre os pêlos do peito, camisa laranja janela desvendando a selva onde se perderia, viu depois, antes de descer os olhos pela linha vertical dos pequenos botões brilhantes, ultrapassar o cinturão de couro para deter-se no volume realçado pela calça branca muito justa esticada contra as coxas que imaginou espessas como o peito (...) (ABREU, 1996:66).

A narrativa se passa em um espaço com uma pista de dança, e seu tempo é, provavelmente, de algumas horas. A linguagem fragmentada utilizada pelo autor sugere o ritmo dos acontecimentos e permite que o leitor enxergue o ambiente através dos olhos das personagens. A fala do narrador é constantemente confundida com a voz de ambas, o que reitera sua identificação com as mesmas e com o espaço descrito:

Três passos, mediu, entupido de álcool, fumo, decibéis e corpos, tem fogo, pode me dizer as horas, qualquer coisa assim, mas o mulatinho cortou o impulso, saiote pregueado, camiseta do flamengo, a bola de futebol numa das mãos, a outra na cintura, deslocando cheiros, gim, suor, esmegma, lux, patchuli, inesperada barreira entre o alvo e a mira (ABREU, 1996:66; destaque meu). 
As personagens se olham por algum tempo, conversam e partem juntas a um "recanto chinês", 9 sob os olhares "estrangeiros" dos que estão do lado de fora daquele espaço onde se encontraram:

Ultrapassaram os táxis estacionados, a malícia contida dos motoristas e uma quase madrugada querendo brotar por trás da cartolina dos edifícios, as duas filas de coqueiros onde lixou as palmas das mãos, e depois a rua verde-vermelho e depois o parque e depois a grama molhada verde sobrenatural do mercúrio (...) (ABREU, 1996:68).

Ambos seguem pelo escuro do jardim e descobrem algumas silhuetas em meio às árvores. $O$ narrador afirma que entre os semelhantes sempre pode haver um inimigo, devido ao monstro comum que os homossexuais enfrentam cotidianamente: a solidão:

Avançam pelo escuro cada vez mais denso até o pequeno templo, missa, ritual, liturgia secreta, ariscas silhuetas entre as folhagens, irmãos de maldição tão solitários que mesmo nos iguais há sempre um inimigo, contraponto de grilos, gemidos e suspiros leves como folhas pisadas numa dança, dentro não, muita bandeira, aqui no canto (ABREU, 1996:68; destaque meu).

O "ritual" é narrado por Abreu com detalhes, o que diferencia sua perspectiva da perspectiva de João Antônio. Trata-se do "corpo-a-corpo com a vida”, mas também de uma narrativa baseada em experiências do próprio autor.

O desfecho do conto permite duas possibilidades de interpretação, como podemos observar a seguir:

(...) e de repente as silhuetas destacadas da massa de folhagens e de repente o cerco e de repente o golpe, suspeita confirmada. Mas antes de a pedra fechada na mão baixar com força contra seu queixo espatifando os dentes e o rosto afundar as folhas apodrecidas sobre a poça de lama da chuva da tarde, âncora dourada, teve tempo de ver, presságio de viagem, e antes de o sangue gotejar sobre a blusa branca, um pouco antes ainda de os estilhaços de imagens e vozes e faces cruzarem seu cérebro em todas as direções, cometa espatifado, chuva sangrenta de

9 É possível que o jardim citado por Caio Fernando Abreu seja a Vista Chinesa, localizada dentro do Parque Nacional da Tijuca, no Rio de Janeiro. 
estrelas, teve tempo de pensar, ridiculamente, e sabia que era assim, que só queria, como uma dor ainda mais aguda, e tanto que chegou a gemer, pelo que estava pensando, não pelo punho fechado muitas vezes contra a barriga, só queria, desesperadamente, um pouco de. Ou: qualquer coisa assim (ABREU, 1996:69; destaque meu).

Como vemos, a suspeita dos "inimigos entre os iguais" é confirmada, e o protagonista é brutalmente espancado. Devido ao título do conto, é possível que o mesmo tenha sido levado a uma armadilha, ou seja, que tenha sido literalmente caçado por seu parceiro. Porém, não podemos nos esquecer de que ambos representam uma transgressão e, desse modo, podem constituir-se em alvos certeiros da intolerância e do preconceito.

O que nos chama a atenção nas últimas linhas do conto são as entrelinhas. A "dor mais aguda" que o protagonista gostaria de sentir relaciona-se a essa solidão latente e, independentemente do nome que damos a essa dor - amor, desejo, gozo -, ele não consegue senti-la, já que é veementemente interrompido. Nesse caso, além de física, a violência é principalmente psicológica, causada pela discriminação.

\section{Os escritores e seus projetos literários}

Como vimos, João Antônio e Caio Fernando Abreu tratam a escrita de forma bastante semelhante, o que se reflete em seus textos jornalísticos e literários. Focar as margens por meio de uma linguagem recriada a partir da fala dos tipos sociais retratados revela o "corpo-acorpo" defendido por João Antônio.

O tema da homossexualidade era bastante recorrente na secada de 1970, ano em que foram escritos os contos analisados. João Antônio, já no Rio de Janeiro, preocupava-se em pintar o quadro mais realista possivel do Brasil, parcialmente estampado nos bairros e na população pobre da capital carioca. Caio Fernando Abreu convivia com o preconceito e a discriminação contra os homossexuais, principais temáticas de sua obra, especialmente nas décadas de 1970 e 1980. 
As diferentes abordagens do tema em questão refletem, a nosso ver, as preocupações dos autores naquele período. João Antônio buscava um jornalismo que "ralasse nos fatos" a fim de se aprofundar nas questões sociais do país, suas desigualdades e desmandes políticos. Por sua vez, Caio Fernando Abreu oferecia a seus leitores a visão "de dentro" do mundo dos homossexuais, desde os lugares que freqüentavam na noite paulistana e carioca às situações de discriminação que eram obrigados a enfrentar. Assim, é impossível não relacionar a vida do escritor gaúcho à sua escrita e, ainda, a seu projeto literário - reiterando, no entanto, que não nos limitamos exclusivamente a essa relação. O escritor nascido em Presidente Altino também se refere com abundância, em seus textos, à sua vida quando ainda era morador do bairro periférico, bem como ao momento em que passou a fazer parte da tão odiada "classe mérdea" ${ }^{10}$

A urgência presente na perspectiva de Abreu diferencia-se da urgência de João Antônio na medida em que reflete sobre suas próprias experiências extremas. Trata-se da "escrita de urgência", um gênero discursivo contemporâneo, em que se inclui a condição homossexual e a escrita da AIDS. Nas palavras de Italo Moriconi,

(...) a literatura de urgência seria a leitura crítica, reflexionante, de textos autorais, ficcionais ou não, e de narrativas de trajetórias de vida / fala / escrita em que se tematizam fatos extremos experienciados pelo autor enquanto pessoa física. $\mathrm{Na}$ cena da teoria, está em pauta a relação entre vida e escrita. $\mathrm{Na}$ cena de um campo delimitado de questões, está a escrita como registro, gráfico, sintoma, estilização, encenação, dramatização de uma experiência extrema (MORICONI, 2006).

Assim, o narrador onisciente de Abreu relata com detalhes essa experiência extrema da discriminação sexual, vivida pelo protagonista do conto, mas também matéria da vida do próprio autor. A perspectiva "de dentro" dos acontecimentos instaura maior subjetividade ao conto e percorre temas como o preconceito e o desejo explícito pelo mesmo sexo,

10 O termo "classe mérdea" foi cunhado pelo próprio autor. 
diferentemente de João Antônio, que entende a homossexualidade como uma falta de opção dos jovens pobres do subúrbio, como já discutimos na análise de seu conto. Trata-se, pois, de uma visão social do fato, muitas vezes abordado pejorativamente pelo autor.

Para Caio Fernando Abreu, a homossexualidade sempre foi um fato difícil de lidar, tanto pelo olhar do "outro" quanto pela solidão. Em carta à amiga Maria Augusta Antoun, datada de 01 de dezembro de $1995,{ }^{11}$ o autor fala a respeito de sua "natureza", expondo claramente como se sentia:

Vera [Antoun, filha de Maria Augusta] foi muito importante na minha vida. Carrego até hoje certa culpa por não ter agido bem com ela. Eu queria casar, ter filhos - foi a única mulher na vida com quem pensei isso - mas ao mesmo tempo isso atraiçoaria minha natureza mais profunda (e mais maldita) (ABREU, 2002:343, destaque meu).

Os "irmãos de maldição" do conto "Caçada”, bem como de tantos outros, são representações baseadas nessa experiência dolorida do escritor. O corpo-a-corpo de Caio Fernando Abreu “(...) é pele com pele, até o nível da cega, da sensivel mucosa” (MORICONI, 2006).

O “corpo-a-corpo com a vida" delineia-se, portanto, de maneiras diferentes nesse dois jornalistas e escritores que tanto marcaram as décadas de 1970 e 1980. Contudo, ambos preocupam-se em imprimir um retrato fiel dos problemas enfrentados cotidianamente pelo povo brasileiro - seja enquanto vítima do preconceito sexual ou da diferença social, seja da classe média paulistana ou morador do subúrbio carioca. João Antônio e Caio Fernando Abreu sangram, pois, abundantemente.

Referências bibliográficas

ABREU, Caio Fernando. Pedras de Calcutá. São Paulo: Companhia das Letras, 1996.

ABREU, Caio Fernando. Cartas. Organização: Italo Moriconi. Rio de Janeiro: Aeroplano, 2002.

11 Caio Fernando Abreu faleceu no dia 25 de fevereiro de 1996, vítima de complicações decorrentes da AIDS. 
ANTÔNIO, João. "Galeria Alaska”. In: Malhação do Judas Carioca. Rio de Janeiro: Civilização Brasileira, 1976.

ANTÔNIO, João. "Corpo-a-corpo com a literatura”. In: Malhação do Judas Carioca. Rio de Janeiro: Civilização Brasileira, 1976.

ANTÔNIO, João. Casa de Loucos. Rio de Janeiro: Civilização Brasileira, 1976.

MORICONI, Italo. "Urgência, orgia, escrita da AIDS (Algumas notas sobre vida / obra, obra / morte)". Conferência apresentada no Seminário Literatura da Urgência, ocorrido no SESC do Rio de Janeiro, de 11 a 13 de setembro de 2006. 